\title{
Advertising Unhealthy Food to Children: on the Importance of Regulations, Parenting Styles, and Media Literacy
}

\author{
Brigitte Naderer $^{1}$ (D)
}

Accepted: 11 November 2020 / Published online: 21 November 2020

(C) The Author(s) 2020

\begin{abstract}
Purpose of Review Childhood obesity is a global health concern. And a number of studies have indicated that food promotions affect children's food attitudes, preferences, and food choices for foods high in fat and sugar, which potentially impacts children's body weight development. This review showcases how children are affected by food promotions, why companies even target children with their promotional efforts, and what makes children so susceptible to promotion of unhealthy food. In addition, this review discusses how regulations, parental styles, and individual media literacy skills can help to contain the potential detrimental effects of food promotions on children's health.

Recent Findings The recent findings indicate that children are affected by food promotions in their preference for unhealthy food and beverages in selection tasks shortly conducted after exposure. Furthermore, results indicate significant effects of food marketing, including enhanced attitudes, preferences, and increased consumption of marketed (predominantly unhealthy) foods connected with a wide range of marketing strategies. Children are particularly vulnerable to promotional efforts and react to it strongly due to their still developing cognitive and social skills as well as their lack in inhibitory control.

Summary This review proposes an applied focus that discusses pathways for regulators, parents, and educators. In the light of the discussed results, a large number of studies on food promotion indicate that there is need to react. In all these measures, however, it is of relevance to consider children's developmental stages to effectively counteract and respond to the potential detrimental effects of food promotions on children's long-term weight development.
\end{abstract}

Keywords Food advertising $\cdot$ Obesity and overweight $\cdot$ Children

\section{Introduction}

Cereals containing high amounts of sugar are promoted as a healthy breakfast full of fibers [1]; candy products are framed as having health attributes beneficial for children's growth or an active lifestyle [2]; and well-liked cartoon characters are used as promotional figures or even present candy and snacks brands as part of a movie narrative to appeal to children [3]. All these examples highlight that products high in sugar, fat, and salt and low in nutritional value (i.e., unhealthy foods) are a big part of children's food environment presented in

This article is part of the Topical Collection on Food Addiction

Brigitte Naderer

brigitte.naderer@ifkw.lmu.de

1 Department of Media and Communication, Ludwig-Maximilians-University Munich, Oettingenstr. 67, 80538 Munich, Germany advertising content. At the same time, we know that children are not consuming the recommended fruit and vegetable rations but tend to overeat on sugary and salty products [e.g., 4]. This can in the long run negatively affect the development of their body weight [5]. And obese children are likely to stay obese when they grow up, which raises serious implications for long-term health concerns, as obesity is connected to a variety of cardiovascular diseases and some types of cancers [6]. But how does advertising content contribute to these health concerns?

\section{Effects of Advertising on Children's Eating Behavior}

Recent content analyses show that children are confronted with high numbers of unhealthy food and beverage depictions. This can be said for traditional advertising such as TV commercials [e.g., 7, 8], for online content targeted at children [9, 
$10]$ and for embedded forms of advertising [11 $\cdot$. For instance, a content analysis of the most popular children's movies over 25 years has shown that Coca-Cola is the most frequently embedded food brand in these movies [1 $\left.1{ }^{\bullet}\right]$. Persuasive messages about food targeted at children furthermore work with strong persuasive tactics. For example, these ads tend to highlight nutritional gains with terms such as "natural" or "fruity." In addition, there is a strong emphasis on enjoyment and excitement for instance by incorporating toys or games. These tactics are used by breakfast cereal manufacturers, fast food chains, and also candy producers $[1,12]$. In addition, unhealthy foods are shown as well liked by popular characters, children know from their favorite movies [3, 11•]. For instance, the "Smurfs" literally fall in love with the candy $m \& m$ 's [13] and the chipmunks in 'Alvin and the Chipmunks' sing an enthusiastic song about their favorite snack UTZ cheeseballs [3]. Food advertisements aimed at children therefore follow a certain strategy which typically entails fun, adventure, fantasy, and popular characters to appeal to the young consumers. All this aims at building a strong positive association with the brand. This is vastly different from food advertising targeted at adults, in which product attributes such as taste and nutritional value are much more prominent $[1,12]$.

The sheer quantity and the persuasive style of unhealthy food and beverage presentations in media and advertising content targeted at children has been in part made responsible for the rising number of childhood obesity. A recent metaanalysis of 17 studies indicates that if children are exposed to unhealthy dietary marketing, their dietary intake significantly increased during or shortly after exposure to advertisements. In addition, children showed a preference for the unhealthy food and beverages promoted in selection tasks shortly conducted after exposure [14]. Another recent review identified 71 qualitative and quantitative effect studies on food marketing and children, which supports these results [15••]. The examined studies indicate significant effects of food marketing, including enhanced attitudes [e.g., 13, 16], preferences [e.g., 17], and increased consumption [e.g., 18] of marketed (predominantly unhealthy) foods connected with a wide range of marketing strategies like brand placements [e.g., 3, 11•, 13], advergames [e.g., 19], social media [20], and product packaging [e.g., 1]. This is verified by another recent meta-analysis on screen advertising on children's dietary intake that concludes exposure to unhealthy food advertising increases immediate calorie consumption in children [21].

Folkvord and colleagues [22] attribute these observed effects of increased appetite and specific food and beverage preferences in their Reactivity to Embedded Food Cues in Advertising Model to the mediating impact of cue reactivity. Cue reactivity connected to food presentations describes heightened psychological and physiological responses with effects such as higher heart rates, gastric activity, and salivation [23-25], as well as increased attention to food depictions [26, 27], and more thoughts about eating [28, 29] when being confronted with food presentations. Following Folkvord et al.'s [22] conceptualization, the level of cue reactivity predicts the subsequent eating behavior. The level of cue reactivity in turn corresponds to the type of food that is presented; how the message presenting the food is delivered; as well as what individual susceptibility factors the audience possesses. Moreover, eating behavior is regarded as both a dependent variable and a contributor to the intensity of the reaction because an already-established behavior influences the future impact on this behavior [22, p. 27].

But why do companies even target children with their promotional efforts; what makes children so susceptible to promotion of unhealthy food; and how can regulations, parental styles, and individual media literacy skills help to contain the potential detrimental effects of food promotions on children's body weight development?

\section{Promotion of Unhealthy Foods}

Companies specifically target children with their promotional efforts, not only because they already want to steer the consumers of tomorrow towards their own brand, but also because children already have a significant spending capacity. This is firstly, because children are an important decisionmaking factor for their parents' purchasing behavior. Thus, they are able to choose products while shopping with their parents, and parents also consider their children's preferences and needs when shopping alone $[13,30]$. Secondly, children themselves are considered relevant consumers, as they have money on their own, particularly to spend on small, relatively cheap products like snacks and candy [13]. And as children are largely unbiased towards brands and are still developing their product preferences, they are considered as particularly receptive to advertising measures [31].

\section{Susceptibility to Unhealthy Food Promotions}

\section{Media Environment and Susceptibility}

Studies indicate that humans inherently show a preference for candy and snacks $[32,33]$ and accordingly if given the choice have a slight predisposition to choose the unhealthy over the healthy option. For instance, a study with infants indicates that babies can already discriminate between the taste of water and a water-sugar solution and that they show a distinct preference for the latter [32]. Sweet taste is evolutionary connected with the save choice, compared to for instance bitter tastes, which could potentially indicate poisonous food to the human body [34]. Hence, children are biologically wired to prefer sweet 
foods and dislike bitterness. Media presentations can now contribute to this inherent preference as they predominantly present and promote unhealthy food often with high levels of sugar, fat, and salt [7-9, 11•] determining the preferences of children $[15 \bullet \bullet$. The food environment children are confronted with builds a regular exposure to certain foods and thus builds awareness and reinforces food familiarity. This can, as a consequence, potentially reduce the phenomenon of food neophobia (i.e., the fear of trying new foods based on the human instinct of self-preservation) for these frequently presented foods [35].

The familiarity with foods is of course formed beyond media presentations, for instance in the family environment [36]. Yet, media presentations shape our perceptions of what we know, like, and how we should act [37]. And as we are prone to eat products we are already familiar with and therefore know whether they will be harmful to us in any way, food presentations in media content shape our perception of the presented foods [36]. Consequently, the predominance of unhealthy food showcased in content analyses [e.g., 7-9, 11•] plays into preexisting preferences and does not help to minimize food neophobia for more healthy products. In sum, this potentially contributes to an unhealthy, unilateral nutrition from a very young age onwards.

\section{Cognitive Development and Literacy}

Children are furthermore considered as relatively receptive to advertising measures, as their cognitive resources are still developing [38]. Hence, they are less literate and less critical when being confronted with advertising messages [39]. In the following, the role of children's age in the context of developmental stages will be discussed. Certain age ranges can be defined that are considered as influential. However, it is relevant to point out that age serves just as a proxy that is correlated with certain cognitive, communicative, and social skills, which are the key contributors to children's understanding of advertising [40-42].

Children under the age of 7 are only able to process simple content and they base their decision on predominantly superficial, obvious factors such as size and color (John's [43] characterization of developmental stages relevant for understanding advertising is based on a traditional Piagetian model). Conspicuous packaging and use of eye-catching characters can thus easily steer their decisions for instance when shopping in the supermarket [e.g., 1]. Children in this developmental stage find it difficult to put themselves in the shoes of others, and this makes it harder for them to understand negotiation situations [43]. In terms of processing persuasive messages, this inability to understand the intent of advertisers does hardly allow them a critical and literate processing of advertising [39]. And while around the age of five, children can recognize the difference between a program and a commercial they still regard advertising as something entertaining and even informative (i.e., in the sense of "this is what I should ask for at my next shopping trip with my parents"). It is only around the age of 8 that children are able to decipher the persuasive intentions behind advertising, yet largely still without being able to object against the advertising claims [31, 44]. Therefore, especially children in the early phases of childhood are perceived as a risk group for strong advertising effects [38, $45,46]$ which is connected to the call of regulations specifically protecting young children $[47 \bullet \bullet]$.

Children aged 7-11 have developed a more complex processing and a more abstract way of thinking [38, 48]. Products are analyzed more deeply and decisions are made based on more than one obvious factor [43]. While younger children see primarily a personal benefit, namely entertainment or information gain in advertising, it is possible for older children to include the perspective of others and start to correctly understand the selling intent of advertising [31]. Children aged 8 and older also are open to the concept that advertisers use lies or exaggeration to sell a product [44]. If children in this age range have developed a certain level of cognitive reflection which is discussed in the concept of the Theory of Mind, their understanding of advertisers' selling intent is considered as particularly high [40]. However, even here, the persuasive understanding during the reception situation is limited and their more critical thinking hardly reduces the desire for the shown products [48-50]. The ability to remember and name the products that appeal to children is significantly expanded in this phase and first preferences towards certain brands and products are formed [44].

Tweens and teens between the ages of 11 and 16 then are considered as entering the most reflective stage [43] with the developing of executive functions progressing until around the age of 18 [39]. Yet, recent studies indicate that children need to be at least 12-14 years old do fully grasp the intentions of advertisers [40,51]. The cognitive skills in tweens and teens are further developed and are getting increasingly similar to adult like processing [39]. Their knowledge of the market, brands, and prices is now at a relatively high level. Tweens and teens understand the persuasive intent of advertising and they can identify and classify advertising tactics tailored to them [43]. This also enables them to recognize misleading information and to partly protect themselves against it [31]. However, the social importance that brands have and the pressure to be in line with their peer group are also particularly strong in this phase, so the social evaluation of products or brands is a decisive factor [43]. The search for information, which is still very limited in younger children, is already at an advanced level and a large number of sources are known and used [52].

In addition to the conceptual understanding of advertising and persuasive intent, children also develop a stronger grasp on their inhibitory control as they grow older. Hence, they are less likely to be easily tempted by the presentation of 
appetizing snacks and candy. This is why age is usually considered as an important susceptibility factor when examining the advertising effects on children's eating behavior [22]. In addition, this also explains why reflection about nutritional aspects of food gets easier for children as they grow older [53•], which can also diminish their susceptibility to unhealthy foods.

\section{Role of Regulations, Parental Mediation, and Media Literacy}

\section{Regulations}

The high number of unhealthy food promotions has been heavily criticized and globally there were initiatives to reduce the marketing of unhealthy food to children (e.g., Australia: [54•]; Chile: [55]; South Korea: [56]; UK: [57]) or at least to diversify the presentations of food products [8]. Diversifying the presentations of food could potentially help to broaden the food environment children are confronted with in media content and in consequence decrease food neophobia for healthy foods [36]. However, regulative programs that often are based on selfregulations of the industry have only been partly successful [58]. For instance, a recent content analysis that examines the success of such self-regulatory efforts has found only a marginal decrease in the presentation of unhealthy foods in promotional efforts targeted at children [54 $]$. Calls for governmental restrictions of food advertising targeted at children are therefore voiced [56]. Yet, these regulations need to consider food promotion from many different angles. As highlighted in the section on effects, a recent review found that online content, games, and embedded food presentations in movies contribute to unhealthy nutrition in children $[15 \bullet \cdot$. Hence, to effectively reach the intended target group, regulations would need to consider to integrate these kinds of food promotions in their regulatory efforts as well $[47 \bullet \bullet]$.

\section{Parental Mediation}

In addition to regulatory efforts, the direct environment of children, specifically their parents, is an important agent that can impact how and in what frequency children are confronted with food advertising. Parents heavily shape children's analogue food environment [36] and they also can act as gatekeepers for their media food environment. Parents in this sense for instance regulate how much children are confronted with advertising messages [59]. They also have the possibility to educate their children about advertising by relying on communication strategies and specific behaviors. For instance, parents can adopt a restrictive mediation, which builds on setting regulations for media and advertising exposure [49, 60], however without getting into much detail about why persuasive content is regarded as content that should be restricted [61]. Furthermore, parents can choose an active mediation route $[49,62]$, where they educate their children on why they would like them to switch channels when a commercial is aired or why they click away ads in a YouTube video [61]. This strategy is seen as particularly promising if combined with co-viewing if parents watch content together with their children and give them commentary on what is shown whether it is an obvious product placement in a movie which they find annoying and they comment on that or whether it is a traditional ad that exaggerates the positive aspects of the presented products which they discuss with their children. Providing this commentary particularly if it contains affective cues [63] can help children to defend themselves against the equally affective messages companies use to persuade their target audience [50].

\section{Media Literacy}

The above-described parental mediation that educates children during the presentation of media content already highlights the parents' role as an important agent to make their children more literate [53, 64]. They thus can help on the one hand to make their children more literate about persuasive strategies advertisers use to sell their products $[47 \cdot \bullet$, $60,63]$. This however relies on the premises that they adequately understand advertising strategies themselves, which is not always provided, particularly for embedded advertising [65]. On the other hand, parents can also contribute in increasing children's health literacy [2]. This can be achieved in a similar manner as described above, by providing them with active mediation strategies about healthy food, i.e., explaining to children why a certain food is good for them [64]. Possessing certain levels of health literacy helps to deceiver the presented messages in food advertising, for instance, if the health benefits of a product are exaggerated $[2,53 \bullet]$.

In addition to literacy measures in a private, informal context, increasing children's media literacy through official literacy trainings is a possibility to empower them to properly process the persuasive attempts of advertisers [66]. For instance, educating them about specific advertising strategies and instruments such as advergames or embedded product placements can increase children's conceptual understanding of advertising [67, 68]. Even though media education is not yet compulsory in educational programs of many countries, this should be changed in the upcoming years [66]. To raise a generation who understands processes of media creation, how you conduct yourself in a media environment, and what persuasive strategies are employed in this context is very relevant [69]. Therefore, by including media literacy programs as a 
compulsory subject [70] and by including education about advertising strategies in these programs [71], a large group of children and adolescents can be educated. Children and adolescents then can work as a channel of reaching their parents and grandparents and thus facilitating knowledge to those who cannot be reached through school programs [66] and who also might have problems understanding the persuasive intent of embedded forms of advertising [65]. Consequently, implementing such literacy programs would help to reach large parts of the society and should increase advertising literacy for many different generations.

\section{Conclusion}

To conclude, food advertising in various forms has an impact on children's eating behavior $[14,15 \cdot \bullet]$ and therefore can have a negative long-term impact on children's development of overweight or obesity. The present review has showcased that we as humans already have an inherent preference particularly for sweet products, and the food environment media presentations create [e.g., 7, 10,11•] reinforces these preferences. In addition, due to the limited development of children's cognitive and social capabilities as well as their still developing inhibitory control, they are particularly vulnerable to food promotions of unhealthy food and beverages [39]. To counteract these undesirable effects of food promotions, there are three possibilities: First, parents can counteract negative effects through regulation and education. While employing an active parental mediation path is a good long-term solution, additionally relying on a more restrictive approach when children are very young seems advisable [53•]. This is based on the consideration of the developmental stage of very young children [43] that highlights that active parental mediation does not necessarily fall on fertile ground for very young kids and that they might need additional cues or a more regulated environment to assure a fair exposure to persuasive content [38]. The consideration of children's developmental stage consequently should guide the educational and regulatory efforts [39]. Hence, for the second pathway of regulations, it is crucial to know the age group content is targeted at. In content particularly targeted at young children, putting regulations in place that require a broad variety of foods to be presented [64]; regulating the employed persuasive strategies [38]; and restricting the amounts of the promoted unhealthy food [56] seem advisable in the eye of the presented results. Lastly, and as the most sustainable pathway, children need to be holistically educated in media literacy, specifically about persuasive strategies starting from an early age on [71]. Children's own literate behavior with media content is indeed the most empowering and sustainable solution in this context.
Funding Open Access funding enabled and organized by Projekt DEAL.

Open Access This article is licensed under a Creative Commons Attribution 4.0 International License, which permits use, sharing, adaptation, distribution and reproduction in any medium or format, as long as you give appropriate credit to the original author(s) and the source, provide a link to the Creative Commons licence, and indicate if changes were made. The images or other third party material in this article are included in the article's Creative Commons licence, unless indicated otherwise in a credit line to the material. If material is not included in the article's Creative Commons licence and your intended use is not permitted by statutory regulation or exceeds the permitted use, you will need to obtain permission directly from the copyright holder. To view a copy of this licence, visit http://creativecommons.org/licenses/by/4.0/.

\section{References}

Papers of particular interest, published recently, have been highlighted as:

- Of importance

•- Of major importance

1. Lavriša Ž, Pravst I. Marketing of foods to children through food packaging is almost exclusively linked to unhealthy foods. Nutrients. 2019;11:1128. https://doi.org/10.3390/nu11051128.

2. Heiss R, Naderer B, Matthes J. Healthwashing in high-sugar food advertising: the effect of prior information on healthwashing perceptions in Austria. Health Promot Int. accepted.

3. Matthes J, Naderer B. Children's consumption behavior in response to food product placements in movies. J Consum Behav. 2015;14: 127-6. https://doi.org/10.1002/cb.1507.

4. Geller KS, Dzewaltowski DA. Longitudinal and cross-sectional influences on youth fruit and vegetable consumption. Nutr Rev. 2009;67:65-76. https://doi.org/10.1111/j.1753-4887.2008.00142. $\mathrm{x}$.

5. Lin BH, Morrison RM. Higher fruit consumption linked with lower body mass index. Food Rev. 2002;25:28-32.

6. World Health Organization WHO. Obesity and overweight. Factsheet June 2016. Retrieved from: http://www.who.int/ mediacentre/factsheets/fs311/en/ [accessed 01 October 2020].

7. Annala M, Vinnari M. Content analysis of tv food advertising using climate impact and a nutritional impact index. Ecol Econ. 2019;159:68-74. https://doi.org/10.1016/j.ecolecon.2019.01.017.

8. Vilaro MJ, Barnett TE, Watson AM, Merten JW, Mathews AE. Weekday and weekend food advertising varies on children's television in the USA but persuasive techniques and unhealthy items still dominate. Public Health. 2017;142:22-30. https://doi.org/10. 1016/j.puhe.2016.10.011.

9. Coates AE, Hardman CA, Halford JCG, Christiansen P, Boyland EJ. Food and beverage cues featured in YouTube videos of social media influencers popular with children: an exploratory study. Front Psychol. 2019a;10:1-14. https://doi.org/10.3389/fpsyg. 2019.02142.

10. Hurwitz LB, Morales ED, Montague H, Lauricella AR, Wartella E. Mobile marketing to children: a content analysis of food and beverage company apps. Public Health. 2016;141:241-4. https://doi. org/10.1016/j.puhe.2016.09.025.

11. Naderer B, Matthes J, Spielvogel I. How brands appear in children's movies. A systematic content analysis of the past 25 years. Int J Adv. 2019;38:237-57. https://doi.org/10.1080/02650487. 2017.1410000 This is an interesting content analysis that 
showcases how children have been confronted with brands in the most popular children's movies of the past 25 years.

12. Boyland EJ, Halford JCG. Television advertising and branding. Effects on eating behavior and food preferences in children. Appetite. 2013;62:236-41. https://doi.org/10.1016/j.appet.2012. 01.032 .

13. Naderer B, Matthes J, Zeller P. Placing snacks in children's movies: cognitive, evaluative, and conative effects of product placements with character product interaction. Int J Adv. 2018;37:852-70. https://doi.org/10.1080/02650487.2017.1348034.

14. Sadeghirad B, Duhaney T, Motaghipisheh S, Campbell NRC, Johnston BC. Influence of unhealthy food and beverage marketing on children's dietary intake and preference: a systematic review and meta-analysis of randomized trials. Obes Rev. 2016;17:945-59. https://doi.org/10.1111/obr.12445.

15.• Smith R, Kelly B, Yeatman H, Boyland E. Food marketing influences children's attitudes, preferences and consumption: a systematic critical review. Nutrients. 2019;11:1-14. https://doi.org/10. $3390 /$ nu 11040875 This is an interesting review that summarizes the most recent insights into the effects of food marketing on children.

16. Dixon H, Niven P, Scully M, Wakefield M. Food marketing with movie character toys: effects on young children's preferences for unhealthy and healthier fast food meals. Appetite. 2017;117:34250. https://doi.org/10.1016/j.appet.2017.07.014.

17. Tarabashkina L, Quester P, Crouch R. Food advertising, children's food choices and obesity: interplay of cognitive defences and product evaluation: an experimental study. Int J Obes. 2016;40:581-6. https://doi.org/10.1038/ijo.2015.234.

18. McGale LS, Halford JCG, Harrold JA, Boyland EJ. The influence of brand equity characters on children's food preferences and choices. J Pediatr. 2016;177:33-8. https://doi.org/10.1016/j.jpeds. 2016.06.025.

19. Folkvord F, Lupiáñez-Villanueva F, Codagnone C, Bogliacino F, Veltri G, Gaskell G. Does a 'protective' message reduce the impact of an advergame promoting unhealthy foods to children? An experimental study in Spain and The Netherlands. Appetite. 2017;112: 117-23. https://doi.org/10.1016/j.appet.2017.01.026.

20. Coates AE, Hardman CA, Halford JCG, Christiansen P, Boyland EJ. The effect of influencer marketing of food and a "protective" advertising disclosure on children's food intake. Pediatr Obes. 2019b;14:1-9. https://doi.org/10.1111/ijpo.12540.

21. Russell SJ, Croker H, Viner RM. The effect of screen advertising on children's dietary intake: a systematic review and meta-analysis. Obes Rev. 2019;20:554-68. https://doi.org/10.1111/obr.12812.

22. Folkvord F, Anschütz DJ, Boyland E, Kelly B, Buijzen M. Food advertising and eating behavior in children. Curr Opin Behav Sci. 2016;9:26-31. https://doi.org/10.1016/j.cobeha.2015.11.016.

23. Jansen A. A learning model of binge eating: cue reactivity and cue exposure. Behav Res Ther. 1998;36:257-72. https://doi.org/10. 1016/S0005-7967[98]00055-2.

24. Nederkoorn C, Smulders FTY, Jansen A. Cephalic phase responses, craving and food intake in normal subjects. Appetite. 2000;35:45-55. https://doi.org/10.1006/appe.2000.0328.

25. Overduin J, Jansen A, Eilkes H. Cue reactivity to food-and bodyrelated stimuli in restrained and unrestrained eaters. Addict Behav. 1997;22:395-404. https://doi.org/10.1016/S0306-4603[97]800020.

26. Naderer B, Binder A, Matthes J, Spielvogel I, Forrai M. Food as an eye-catcher. An eye-tracking study on children's attention to healthy and unhealthy food presentations as well as non-edible objects in audiovisual media. Pediatr Obes. 2020;15:1-9. https:// doi.org/10.1111/ijpo.12591.

27. Spielvogel I, Matthes J, Naderer B, Karsay K. A treat for the eyes. An eye-tracking study on children's attention to unhealthy and healthy food cues in media content. Appetite. 2018;125:63-71. https://doi.org/10.1016/j.appet.2018.01.033.

28. Castellanos EH, Charboneau E, Dietrich MS, Park S, Bradley BP, Mogg K, et al. Obese adults have visual attention bias for food cue images: evidence for altered reward system function. Int J Obes. 2009;33:1063-73. https://doi.org/10.1038/ijo.2009.138.

29. Nijs IM, Muris P, Euser AS, Franken IH. Differences in attention to food and food intake between overweight/obese and normal-weight females under conditions of hunger and satiety. Appetite. 2010;54: 243-54. https://doi.org/10.1016/j.appet.2009.11.004.

30. Wilson G, Wood K. The influence of children on parental purchases during supermarket shopping. Int J Consum Stud. 2004;28:329-36. https://doi.org/10.1111/j.1470-6431.2004.00393.x.

31. Buijzen M, van Reijmersdal EA, Owen LH. Introducing the PCMC model: an investigative framework for young people's processing of commercialized media content. Commun Theory. 2010;20:42750. https://doi.org/10.1111/j.1468-2885.2010.01370.x.

32. Desor JA, Maller O, Turner RE. Taste in acceptance of sugars by human infants. J Comp Physiol Psychol. 1973;84:496-501. https:// doi.org/10.1037/h0034906.

33. Harris G, Thomas A, Booth DA. Development of salt taste in infancy. Dev Psy. 1990;26:534-8.

34. Mennella JA, Bobowski NK. The sweetness and bitterness of childhood: insights from basic research on taste preferences. Phys Behav. 2015;152:502-7. https://doi.org/10.1016/j.physbeh.2015. 05.015 .

35. Birch LL, Marlin DW. I don't like it; I never tried it: effects of exposure on two-year-old children's food preferences. Appetite. 1982;3:353-60. https://doi.org/10.1016/S0195-6663[82]80053-6.

36. Birch LL, Fisher JO. Development of eating behaviours among children and adolescents. Pediatrics. 1998;101:539-49.

37. Bandura A. Social cognitive theory of mass communications. In: Bryant J, Zillman D, editors. Media effects: advances in theory and research. Hillsdale: Lawrence Erlbaum; 2002.

38. Rozendaal E, Lapierre MA, van Reijmersdal EA, Buijzen M. Reconsidering advertising literacy as a defense. Med Psychol. 2011b;14:333-54. https://doi.org/10.1080/15213269.2011. 620540.

39. Hudders L, De Pauw P, Cauberghe V, Panic K, Zarouali B, Rozendaal E. Shedding new light on how advertising literacy can affect children's processing of embedded advertising formats: a future research agenda. J Adv. 2017;46:333-49. https://doi.org/ 10.1080/00913367.2016.1269303.

40. Lapierre MA. Development and persuasion understanding: predicting knowledge of persuasion/selling intent from children's theory of mind. J Commun. 2015;65:423-42. https://doi.org/10. 1111 jicom. 12155.

41. Wright P, Friestad M, Boush DM. The development of marketplace persuasion knowledge in children, adolescents, and young adults. $\mathrm{J}$ Public Policy Mark. 2005;24:222-33. https://doi.org/10.1509/ jppm.2005.24.2.222.

42. Friestad M, Wright P. The persuasion knowledge model: how people cope with persuasion attempts. J Consum Res. 1994;21:1-31. https://doi.org/10.1086/209380.

43. John DR. Consumer socialization of children: a retrospective look at twenty-five years of research. J Consum Res. 1999;26:183-213. https://doi.org/10.1086/209559.

44. Ward S, Wackman DB, Wartella E. How children learn to buy. Beverly Hills: Sage; 1977.

45. Rozendaal E, Buijzen M, Valkenburg PM. Children's understanding of advertiser's persuasive tactics. Int J Adv. 2011a;30:329-50. https://doi.org/10.2501/IJA-30-2-329-350.

46. Zarouali B, De Pauw P, Ponnet K, Walrave M, Poels K, Cauberghe $\mathrm{V}$, et al. Considering children's advertising literacy from a methodological point of view: past practices and future recommendations. J 
Curr Issues Res Advert. 2019;40:196-213. https://doi.org/10.1080/ 10641734.2018.1503109.

47.• De Jans S, Van de Sompel D, Hudders L, Cauberghe V. Advertising targeting young children: an overview of 10 years of research (2006-2016). Int J Adv. 2019;38:173-206. https://doi. org/10.1080/02650487.2017.1411056 This review gives a great overview of the past years of research on how children process advertising messages.

48. Buijzen M, Mens C. Adult mediation of television advertising effects. J Child Media. 2007;1:177-91. https://doi.org/10.1080/ 17482790701339233.

49. Naderer B, Matthes J, Marquart F, Mayrhofer M. Children's attitudinal and behavioral reactions to product placements: investigating the role of placement frequency, placement integration, and parental mediation. Int J Adv. 2018b;37:236-55. https://doi.org/10.1080/ 02650487.2016.1218672.

50. Nairn A, Fine C. Who's messing with my mind? The implications of dual-process models for the ethics of advertising to children. Int $\mathrm{J}$ Adv. 2008;27:447-70. https://doi.org/10.2501/ S0265048708080062.

51. Rozendaal E, Buijzen M, Valkenburg PM. Comparing children's and adults' cognitive advertising competences in the Netherlands. J Child Media. 2010;4:77-89. https://doi.org/10.1080/ 17482790903407333.

52. Moore RL, Stephens LF. Some communication and demographic determinants of adolescent consumer learning. J Consum Res. 1975;2:80-92. https://doi.org/10.1086/208619.

53. Binder A, Naderer B, Matthes J, Spielvogel I. Fiction is sweet. The impact of media consumption on the development of children's nutritional knowledge and the moderating role of parental food-related mediation. A longitudinal study. Nutrients. 2020;12:1-11. https://doi. org/10.3390/nu12051478 This is an important study that examines the relationship of children's nutritional knowledge and their media consumption in a longitudinal design.

54. Watson WL, Lau V, Wellard L, Hughes C, Chapman K. Advertising to children initiatives have not reduced unhealthy food advertising on Australian television. J Public Health. 2017;39:78792. https://doi.org/10.1093/pubmed/fdx004. This relevant study examines the effectiveness of regulations employed to minimize the presence of unhealthy food advertising.

55. Correa T, Reyes M, Taillie LS, Corvalán C, Dillman Carpentier FR. Food advertising on television before and after a national unhealthy food marketing regulation in Chile, 2016-2017. Am J Public Health. 2020:1-6. https://doi.org/10.2105/AJPH.2020.305658.

56. Kelly B, Hebden L, King L, Xiao Y, Yu Y, He G, Li L., Zeng L., Hadi H., Karupaiah T., Hoe N.S., Noor M.I., Yoon J., Kim H. Hoe, N. S. Children's exposure to food advertising on free-to-air television: an Asia-Pacific perspective. Health Promot Int 2016:31:144 152. Doi:https://doi.org/10.1093/heapro/dau055.

57. Whalen R, Harrold J, Child S, Halford J, Boyland E. Children's exposure to food advertising: the impact of statutory restrictions. Health Promot Int. 2019;34:227-35. https://doi.org/10.1093/ heapro/dax044.

58. Wicks JL, Warren R, Fosu I, Wicks RH. Dual-modality disclaimers, emotional appeals, and production techniques in food advertising airing during programs rated for children. J Adv. 2009;38:93-105. https://doi.org/10.2753/JOA0091-3367380407.
59. Cornish SL. 'Mum, can I play on the internet?' Parents' understanding, perception and responses to online advertising designed for children. Int J Adv. 2014;33:437-73. https://doi.org/10.2501/IJA33-3-437-473.

60. Hudders L, Cauberghe V. The mediating role of advertising literacy and the moderating influence of parental mediation on how children of different ages react to brand placements. J Consum Behav. 2018;17:197-210. https://doi.org/10.1002/cb.1704.

61. Buijzen M, Valkenburg PM. Parental mediation of undesired advertising effects. J Broadcast Electron Media. 2005;49:153-65. https://doi.org/10.1207/s15506878jobem4902_1.

62. Buijzen M, Rozendaal E, Moorman M, Tanis M. Parent versus child reports of parental advertising mediation: exploring the meaning of agreement. J Broadcast Electron Media. 2008;52:509-25. https://doi.org/10.1080/08838150802437180.

63. Buijzen M. Reducing children's susceptibility to commercials: mechanisms of factual and evaluative advertising interventions. Media Psychol. 2007;9:411-30. https://doi.org/10.1080/ 15213260701291361.

64. Naderer B, Matthes J, Binder A, Marquart F, Mayrhofer M, Obereder A, et al. Shaping children's healthy eating habits with food placements? Food placements of high and low nutritional value in cartoons, children's BMI, food-related parental mediation strategies, and food choice. Appetite. 2018a;120:644-53. https:// doi.org/10.1016/j.appet.2017.10.023.

65. Boerman SC, van Reijmersdal EA. Informing consumers about hidden advertising. A literature review of the effects of disclosing sponsored content. Adv N For Med: Cur Res Imp Mar. 2016:11546. https://doi.org/10.1108/978-1-78560-313-620151005.

66. van Reijmersdal EA, Rozendaal E. Transparency of digital native and embedded advertising: opportunities and challenges for regulation and education. Communications. 2020;3:378-88. https://doi. org/10.1515/commun-2019-0120.

67. An S, Kang H. Advertising or games? Advergames on the internet gaming sites targeting children. Int J Advert. 2014;33:509-32. https://doi.org/10.2501/IJA-33-3-509-532.

68. Hudders L, Cauberghe V, Panic K. How advertising literacy training affect children's responses to television commercials versus advergames. Int J Advert. 2016;35:909-31. https://doi.org/10. 1080/02650487.2015.1090045.

69. Livingstone S. Media literacy and the challenge of new information and communication technologies. Commun Rev. 2004;7:3-14. https://doi.org/10.1080/10714420490280152.

70. Turner KH, Jolls T, Hagerman MS, O’Byrne W, Hicks T, Eisenstock B, et al. Developing digital and media literacies in children and adolescents. Pediatrics. 2017;140:122-6. https://doi.org/ 10.1542/peds.2016-1758P.

71. Livingstone $\mathrm{S}$, Helsper EJ. Does advertising literacy mediate the effects of advertising on children? A critical examination of two linked research literatures in relation to obesity and food choice. $\mathrm{J}$ Commun. 2006;56:560-84. https://doi.org/10.1111/j.1460-2466. 2006.00301.x.

Publisher's Note Springer Nature remains neutral with regard to jurisdictional claims in published maps and institutional affiliations. 